\title{
Closed Reduction and Percutaneous Pinning for Supracondylar Fractures of Humerus in Vietnamese Children
}

\author{
Dung Tran Trung ${ }^{1,2}$, Nam Le Van ${ }^{2}$, Vien Nguyen Huu ${ }^{2}$, Chinh Dao Nguyen ${ }^{2}$, Ha Nguyen Ngoc ${ }^{1}$, Vu Thi Nga $^{3}$, Toi Chu Dinh $^{4}$ \\ ${ }^{1}$ Hanoi Medical University, Hanoi, Vietnam; ${ }^{2}$ Saint Paul hospital, Hanoi, Vietnam; ${ }^{3}$ Institute for Research and Development, \\ Duy Tan University, 03 Quang Trung, Danang, Vietnam; ${ }^{4}$ Department of Human and Animal Physiology, Faculty of Biology, \\ Hanoi National University of Education, Hanoi, Vietnam
}

\begin{abstract}
Citation: Tran Trung D, Le Van N, Nguyen Huu V, Dao Nguyen C, Nguyen Ngoc H, Nga VT, Chu Dinh T. Closed Fractures of Humerus in Vietnamese Shildracondylar Access Maced J Med Sci. 2019 Dec 30; 7(24):4194-4198. https://doi.org/10.3889/oamjms.2019.355

Keywords: Supracondylar of the humerus fracture; CRPP. Garland classification: Flynn 's criteria

Correspondence: Toi Chu Dinh Departhent of Hum and Anima Physiology, Faculty of Biology, Hanoi Naliona and Animal Physiology, Faculty of Biology, Hanoi Nationa chudinhto@@hnue.edu.vn

Received: 10-Sep-2019; Revised: 20-Nov-2019; Received: 10-Sep-2019; Revised: 20-Nov-2019; Copyright: $\odot 2019$ Dung Tran Trung, Nam Le Van, Vien Nguyen Huu, Chinh Dao Nguyen, Ha Nguyen Ngoc, $\mathrm{V}$ distributed under the terms of the Creative Commons Attribution-NonCommercial 4.0 International License (CC BY-NC 4.0)

Funding: This research did not receive any financia cupport

Competing Interests: The authors have declared that no competing interests exist
\end{abstract}

\begin{abstract}
BACKGROUND: Pediatric supracondylar humerus fracture (SHF) is a complicated injury which can result in severe sequela. Nowadays, closed reduction and percutaneous pinning (CRPP) is the most popular treatment.

AIM: This study had two aims (1) checking the result of treating pediatric SHF patients without neurovascular injury by CRPP under image intensifier, and (2) analysing neurovascular complications of CRPP in treating these patients.

METHODS: We conducted a research on 42 patients from February 2018 to March 2019. The age of patients ranged from 3 to 11 years old, with a mean of 5 . There was a male predominance with a male / female ratio of $3 / 1$. The average duration of the procedure was 46 minutes, and there was no failed case.

RESULTS: Result evaluation based on Flynn criteria (1974): $85.74 \%$ excellent, $9.5 \%$ good, $2.38 \%$ fair, and $2.38 \%$ poor. There was 1 patient how got ulnar nerve injury complication after medial-lateral crossed pinning, making up $2.38 \%$ of all cases. This case was a late admission - 3 days after being injured - and the elbow was badly swollen, so locating the medial condyle for pin placement was very problematic, this the ulnar nerve could be damaged during K-wire pinning. The K-wires are removed after 4 weeks.
\end{abstract}

CONCLUSION: CRPP under image intensifier in treating pediatric supracondylar humerus fracture is an effective treatment and with good treatment result.

\section{Introduction}

SHF account for 60 percent of all elbow fractures in kids with a maximum incidence between 4 and 7 years of age [1]. The fracture typically happens to owe to a falling out of an elbow joint hyperextension of an extended side. These fractures were previously handled with casting or traction in the closed decrease [2]. The method, however, has usually been abandoned due to problems in keeping appropriate alignment and circulation with the limb at the same time, especially with displaced bones (type II and III Gartland). The present technique for treating displaces fractures is closed decrease with percutaneous pin stabilisation, allowing casting in larger elbow extension [3], [4], [5], [6], [7].

Two significant complications connected with this fracture's percutaneous pinning are iatrogenic ulnar nerve injury and decrease loss, cubitus varus / valgus growth or deformity of hyperextension.

There continues a discussion about the ideal pin setup that gives sufficient stability of the fracture to preserve reductions in bondage and to minimise the risk of neurovascular damage. One popular technique of fixation is the cross-pin configuration, where on the pin is placed at the lateral epicondyle and the other at the medial epicondyle. Although this setup has been linked with adequate reproducible stabilisation of the fracture, there is a danger of complications such as ulnar nerve and brachial artery injury when the medial pin is inserted, or periprosthetic infection which will result in the severe sequel. Therefore, the research aimed to assess the outcome of the treatment of patients with pediatric 
supracondylar humerus fracture without neurovascular complications of this method on them.

\section{Methods}

From February 2018 to March 2019, 42 cases of SHF were performed in our department. Twenty-seven cases were found to be Gartland type III fracture [8] (with a completely displaced extension fracture type). Demographic, examination, radiological data were recorded from medical documents. Also, the patients were called back for history and physical examination in a special follow-up assessment clinic. All final assessments were performed by one of the authors.

During this review, we also noted the delayed time to admission and whether the patient and been treated elsewhere before being admitted to our centre. The timing of the operative procedure, the preoperative neurovascular status of the forearm and the hand, the anaesthetic time, other associated injuries, and the postoperative morbidity were all documented [9].

The instances have been handled by CRPP used image intensifier at the earliest possible time (Figure 1).

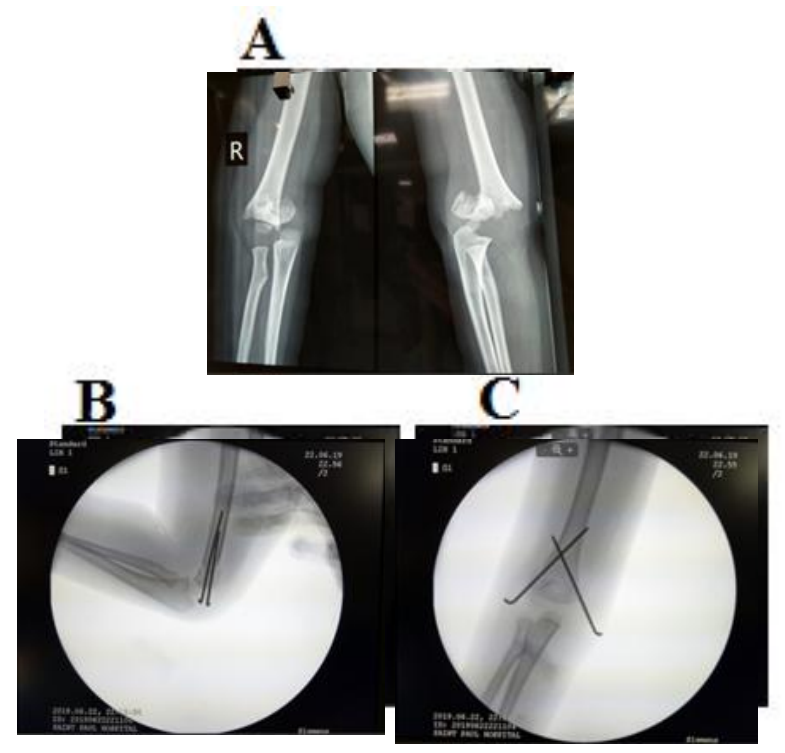

Figure 1: Xray of a 7-year-old boy with supracondylar of the right humerus fracture grade IV (Garland classification); A) Pre-op; B) and C) Post-op Xray of the same patient under image intensifier

Open reduction and pinning were to be performed if the closed reduction and pining failed. For closed pining, a modified technique was performed. A particularly contracted small arm table was used rather than the Bracket inverted in the $U$ form of Flynn, which we found difficult to use with the image intensifier. Using the special armboard, the arm was the table is solved using bandaging, and the patient lay in the seated position with the abducted arm $90^{\circ}$. The arm could be imaged easily in both the AP and lateral views.

During the reduction, the bandage was intended to immobilise the top armed forces, ameliorate them and to allergic, he reduced fracture when the pins were inserted. Our study applied the cross pining technique with one Kirschner wire inserted medially and another laterally the primary benefit of the crossed pin is greater stability, which prevents secondary displacement and malunion [10].

All pins were twisted beyond the skin at the correct angles and protected by a lengthy cast arm. In the outpatient clinic at the end of the $4^{\text {th }}$ week, the cast and the pins were removed without anaesthesia depending on the radiological assessment. Mobilisation exercise was performed under the supervision of a physiotherapist for children $>4$ years old until the elbow regained $\approx 85 \%$ of the normal range of motion.

\section{Results}

\section{Age and Sex Distribution}

Among the 42 cases with SHF, the proportion between male and female was 3: 1 (Figure 2). The peak incidence of the fracture in this study was at the age of 6 , with a gradual and significant decrease to the age of 10 and after.

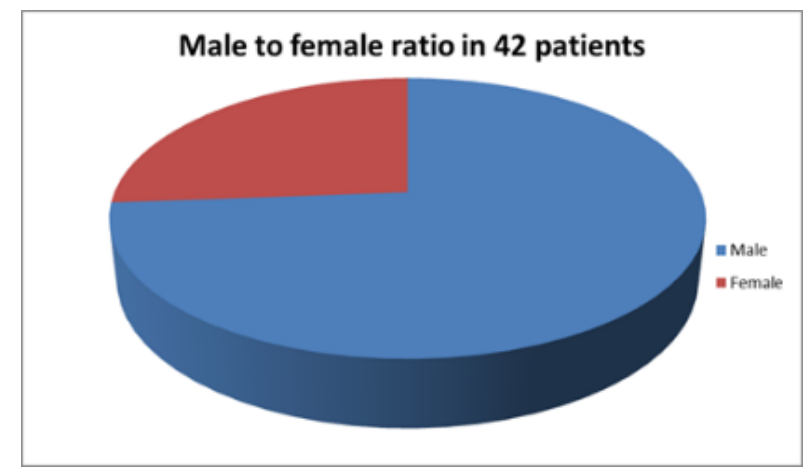

Figure 2: Gender ratio

The peak incidence of the fracture in this study was at the age of 6 , with a gradual and significant decrease to the age of 10 and after (Figure 3).

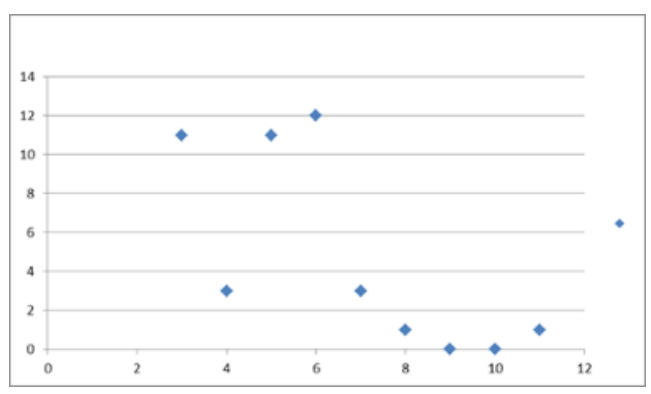

Figure 3: Age distribution of 42 patients 


\section{Side of fracture}

Twenty-five patients had a fracture of the dominant right side, and 17 involved the nondominant left side (ratio 1: 0,68) (Figure 4).

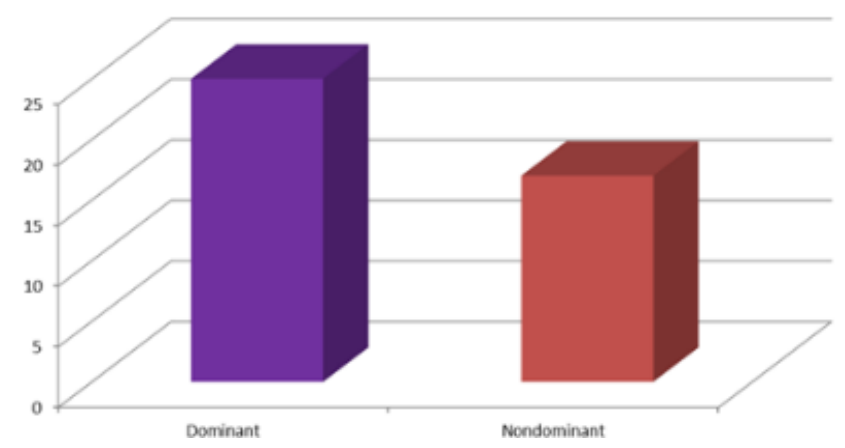

Figure 4: Side of fracture

\section{Time of presentation}

Most of the patients submitted on the injury day. However, $16.7 \%$ sought hospital treatment after a delay of $>24 \mathrm{~h}$. For those cases that presented late, many had initially sought various forms of traditional medicine treatment (Table 1).

Table 1: Time of presentation

\begin{tabular}{lc}
\hline Time of presentation & Patient \\
\hline$<24 \mathrm{~h}$ & $35(83.3 \%)$ \\
$>24 \mathrm{~h}$ & $7(16.7 \%)$ \\
\hline
\end{tabular}

\section{Associated Injuries}

Two patients $(4.7 \%)$ had ipsilateral fractures. They were fractures of the distal radius. At the moment of presentation, there was no case of related neurological injury. 2 people had radial pulse absent at presentation. Still, the clinical assessments were normal so there was no exploration of the radial artery performed, and the pulse fully recovered 12 hours after the operation (Table 2).

Table 2: Associated injuries

\begin{tabular}{lc}
\hline Associated injuries & Patient \\
\hline Distal radius Fx & 2 \\
Pulseless radial artery & 2 \\
Total & 4 \\
\hline
\end{tabular}

\section{Treatment}

All the 42 types II or III patients received primary CRPP. Thirty-nine patients were available for a complete detailed assessment with a follow-up period ranging from 2 to 12 months (average 7.3 months) (Table 3 ).

\section{Table 3: Periods of follow-up}

\begin{tabular}{lc}
\hline Time follow-up & Patient \\
\hline 2 to 12 months & 39 \\
Non-information & 3 \\
Total & 42 \\
\hline
\end{tabular}

Cross pinning was used in all cases. Smooth Kirschner wire of $1.6 \mathrm{~mm}$ diameter was used. There was
1 case got prosthetic osteomyelitis and one iatrogenic ulnar nerve palsy with cross pinning. The one with ulnar nerve palsy fully recovered after 8 months while the one with osteomyelitis had to be re-operated once more and then got elbow stiffness. $5 \%$ of patients were operated within 24 hours of receipt and $93 \%$ were operated within the first 48 hours. The mean anaesthesia time required for the closed reduction and pinning procedure was $46 \mathrm{~min}$. The length of stay in hospital ranged between 1 and 5 days (mean 2 days).

\section{Final Assessment}

Of the 39 cases with CRPP and complete subsection assessment, 3 cases $(7.7 \%)$ had $>10$ degrees of deficit in the elbow movement spectrum.

None had a loss of motion of more than $20^{\circ}$. Two $(5.1 \%)$ had varus deformity $>10^{\circ}$ compared to the normal side. None had varus deformity $>20^{\circ}$. The Flynn criteria were used to assess the results of treatment [11]. Excellent to good results (loss in carrying angle and elbow motion of $<10$ degrees) were achieved in $82 \%$ (Table 4).

Table 4: Flynn's criteria for the outcome of supracondylar fracture of the humerus in children

\begin{tabular}{lcc}
\hline Evaluation & $\begin{array}{c}\text { The factor of cosmetics: } \\
\text { angle of transport }\left({ }^{\circ}\right)\end{array}$ & $\begin{array}{c}\text { Functional factor } \\
\text { loss of movement }\left({ }^{\circ}\right)\end{array}$ \\
\hline Excellent & 38 & 40 \\
$0^{\circ}-5^{\circ}$ & $90.5 \%$ & $95.2 \%$ \\
Good & 3 & 1 \\
$6^{\circ}-10^{\circ}$ & $7.1 \%$ & $2.4 \%$ \\
Fair & 0 & 1 \\
$11^{\circ}-15^{\circ}$ & 1 & $2.4 \%$ \\
Poor & $2.4 \%$ & 0 \\
$>15^{\circ}$ & 42 & 42 \\
Total & $100 \%$ & $100 \%$ \\
\hline
\end{tabular}

According to parental evaluation, $90 \%$ considered their children to have good elbow movement; all of them regarded the function as good, and no patient had any pain at the elbow joint.

We subjected various parameters to statistical analysis for correlation. The only positive correlation was the deviation of carrying angle between the injured and normal side and the difference in Baumann's angles measured on radiographs taken during surgery and on the day of the final assessment, which well correlated (Pearson's reference coefficient of 0.4920 and $p<0.001$ ).

\section{Discussion}

Displaced SHF in children is difficult to treat. As a result, various modes of treatment had been advocated in the past. Simple plaster immobilisation no longer seems acceptable. The problem that the orthopaedic surgeon has to face in choosing this mode of treatment is obvious. To firmly immobilise the reduced fracture, the elbow must be hyper-flexed, which in turn might predispose to vascular compromise as ischemical contracture of 
Volkmann. Skin traction or skeletal traction is generally unaccepted because of the long hospital stay and the difficulties in monitoring the fracture alignment [12].

ORIF requires surgical dissection in an already swollen elbow, which might be hazardous. Also, the open reduction has been associated with a greater residual rigidity in the elbow joint and a substantial varus deformity proportion [13].

Fowles and Kassab [14] and Flynn et al., [11], were known for their pioneering work on CRPP. Our research further supports the fact that a good outcome can be obtained with this method of treatment. It was shown in this study that $95.24 \%$ of cases had Excellent to good result using Flynn's original criteria of assessment [11] with 7.3 months of average tracking [15]. None had varus deformity $>20^{\circ}$. Particularly notable was the achievement of the elbow joint movement. Only $7.7 \%$ of cases had stiffness $>10 \%$. In comparison with several published series of CRPP, the overall excellent to good results in this series is equal to the average of $90-95 \%$ [2], [11], [13], [16].

The overall open reduction rate in our study was $2.38 \%$ (1 case). That case was an 11-year-old male patient with a bodyweight of $55 \mathrm{~kg}$ and Gartland type III fracture. The muscle tone of the arm was high even under general anaesthesia, therefore, closed reduction failed and we had to shift to open procedure. The cross-pinning method was applied in every case. In 4 cases, one more lateral smooth Kirschner wires were used with satisfactory results. The operating time was also decreased significantly in our study.

We found that the adoption of the modified supine positioning of the patient greatly improved many intraoperative population, reduction, and imaging. The primary goals were achieving good initial reduction and good Kirschner wire placement.

In correlating the results of treatment with various parameters, we found no correlation with age, sex, time of presentation, or side of the fracture. The only important correlation was Baumann angle difference before and instantly after decrease was considerably associated with follow-up angles and axial defect $(p<0.001)$. Thus, it would be reasonable to recommend taking a proper radiograph immediately after reduction, measuring Baumann's angle accurately and comparing the results with the normal side. By fixing the reduced fracture in $<5^{\circ}$ of deviation from the normal Baumann's angle, the results could be further improved. This was the advance of procedure performed under the intensified image.

The lack of the pulse was no sign that the artery had been investigated. The clinical assessment of the distal circulation was more important. After effective, fast fracture decrease and fixation, the two instances with no radial pulse had constant healthy distal circulation without residual complications. This is in agreement with the findings of Shaw's series [17].

There was $1(2.38 \%)$ nerve palsies detected post operation which had a complete recovery after 8 months.
Like many other investigators, we recommend adopting a more conservative approach to associated nerve palsies. We referred this patient to the rehabilitation department with neurological agents prescribed. Ipsilateral fractures were not uncommon [18], [19].

About $4.7 \%$ of our cases had such fractures, mostly of the distal radius. They should be reduced and internally fixed appropriately.

From this series we can conclude that cross percutaneous pinning after meticulously closed reduction under good radiographic imaging and anaesthesia is a reliable and secure method for the treatment of type II, III completely displaces SHF in children.

\section{Ethical approval}

This study is approved by Saint Paul hospital. The date is a meticulous, sufficient collection, accurate analysis, scientific, confidence.

\section{Informed consent}

The consent and commitment were signed by the patients in the Study.

\section{Reference}

1. Farnsworth CL, Silva PD, Mubarak SJ. Etiology of supracondylar humerus fractures. J Pediatr Orthop. 1998; 18(1):38-42. https://doi.org/10.1097/01241398-199801000-00008 PMid:9449099

2. Pirone AM, Graham HK, Krajbich JI. Management of displaced extension-type supracondylar fractures of the humerus in children. The Journal of bone and joint surgery. American volume. 1988; 70(5):641-50. https://doi.org/10.2106/00004623-198870050-00002

3. Vaquero-Picado A, González-Morán G, Moraleda L.

Management of supracondylar fractures of the humerus in children. EFORT open rev. 2018; 3(10):526-40.

https://doi.org/10.1302/2058-5241.3.170049 PMid:30662761 PMCid:PMC6335593

4. Wingfield JJ, et al. Open reduction techniques for supracondylar humerus fractures in children. JAAOS-Journal of the American Academy of Orthopaedic Surgeons. 2015; 23(12):e72-e80. https://doi.org/10.5435/JAAOS-D-15-00295 PMid:26507292

5. Barton KL, et al. Reliability of a modified Gartland classification of supracondylar humerus fractures. Journal of Pediatric Orthopaedics. 2001; 21(1):27-30.

https://doi.org/10.1097/01241398-200101000-00007 PMid:11176349

6. Skaggs DL, et al. How safe is the operative treatment of Gartland type 2 supracondylar humerus fractures in children? Journal of Pediatric Orthopaedics. 2008; 28(2):139-141. 


\section{https://doi.org/10.1097/BPO.0b013e3181653ac8 PMid:18388704}

7. Skaggs $\mathrm{DL}$, et al. Lateral-entry pin fixation in the management of supracondylar fractures in children. JBJS. 2004; 86(4):702-707. https://doi.org/10.2106/00004623-200404000-00006 PMid:15069133

8. Gartland JJ. Management of supracondylar fractures of the humerus in children. Surg Gynecol Obstet. 1959; 109(2):145-54

9. Williamson DM, et al. Normal characteristics of the Baumann (humerocapitellar) angle: an aid in assessment of supracondylar fractures. J Pediatr Orthop. 1992; 12(5):636-9.

https://doi.org/10.1097/01241398-199209000-00014 PMid:1517426

10. Lee KM, et al. Medial and lateral crossed pinning versus lateral pinning for supracondylar fractures of the humerus in children: decision analysis. J Pediatr Orthop. 2012; 32(2):131-8. https://doi.org/10.1097/BPO.0b013e3182471931 PMid:22327446

11. Flynn JC, Matthews JG, Benoit RL. Blind pinning of displaced supracondylar fractures of the humerus in children. Sixteen years' experience with long-term follow-up. J Bone Joint Surg Am. 1974; 56(2):263-72. https://doi.org/10.2106/00004623-197456020-00004 PMid:4375679

12. Sutton WR, et al. Displaced supracondylar humeral fractures in children. A comparison of results and costs in patients treated by skeletal traction versus percutaneous pinning. Clin Orthop Relat Res. 1992; (278):81-7. https://doi.org/10.1097/00003086199205000-00013

13. France J, Strong M. Deformity and function in supracondylar fractures of the humerus in children variously treated by closed reduction and splinting, traction, and percutaneous pinning. J
Pediatr Orthop. 1992; 12(4):494-8.

https://doi.org/10.1097/01241398-199207000-00015 PMid:1613094

14. Fowles JV, Kassab MT. Displaced supracondylar fractures of the elbow in children. A report on the fixation of extension and flexion fractures by two lateral percutaneous pins. J Bone Joint Surg Br. 1974; 56B(3):490-500. https://doi.org/10.1302/0301$\underline{620 X .56 B 3.490}$

15. Pretorius J, Rollinson P, Rasool M. Outcome of displaced supracondylar fractures in children after manipulation and backslab. SA Orthopaedic Journal. 2015; 14(4):35-41. https://doi.org/10.17159/2309-8309/2015/v14n1a4

16. Boyd DW, Aronson DD. Supracondylar fractures of the humerus: a prospective study of percutaneous pinning. Journal of pediatric orthopedics. 1992; 12(6):789-794.

https://doi.org/10.1097/01241398-199211000-00017 PMid:1452752

17. Shaw BA, et al., Management of vascular injuries in displaced supracondylar humerus fractures without arteriography. Journal of orthopaedic trauma. 1990; 4(1):25-29.

https://doi.org/10.1097/00005131-199003000-00004

PMid:2313426

18. Biyani A, Gupta S, Sharma J. Ipsilateral supracondylar fracture of humerus and forearm bones in children. Injury. 1989; 20(4):203207. https://doi.org/10.1016/0020-1383(89)90112-5

19. Williamson D, Cole W. Treatment of ipsilateral supracondylar and forearm fractures in children. Injury. 1992; 23(3):159-161. https://doi.org/10.1016/S0020-1383(05)80034-8 